\title{
AN ASSESSMENT OF LIFE-CYCLE FUNDS
}

\author{
Mauricio Soto, Robert K. Triest, Alex Golub-Sass, and Francesca Golub-Sass* \\ CRR WP 2008-10 \\ Released: May 2008 \\ Draft Submitted: April 2008
}

\author{
Center for Retirement Research at Boston College \\ Hovey House \\ 140 Commonwealth Avenue \\ Chestnut Hill, MA 02467
}

Tel: 617-552-1762 Fax: 617-552-0191

http://www.bc.edu/crr

\footnotetext{
* Mauricio Soto is a senior research associate at the Center for Retirement Research at Boston College (CRR). Robert K. Triest is a visiting scholar at the CRR and a Senior Economist and Policy Advisor at the Federal Reserve Bank of Boston. Alex Golub-Sass and Francesca Golub-Sass are research associates at the CRR. The research reported herein was performed pursuant to a grant from the U.S. Social Security Administration (SSA) funded as part of the Retirement Research Consortium. The opinions and conclusions expressed are solely those of the authors and should not be construed as representing the opinions or policy of SSA, any agency of the Federal Government, the Federal Reserve Bank of Boston, or Boston College.

(C) 2008, by Mauricio Soto, Robert K. Triest, Alex Golub-Sass, and Francesca GolubSass. All rights reserved. Short sections of text, not to exceed two paragraphs, may be quoted without explicit permission provided that full credit, including $@$ notice, is given to the source.
} 


\title{
About the Center for Retirement Research
}

The Center for Retirement Research at Boston College, part of a consortium that includes parallel centers at the University of Michigan and the National Bureau of Economic Research, was established in 1998 through a grant from the Social Security Administration. The Center's mission is to produce first-class research and forge a strong link between the academic community and decision makers in the public and private sectors around an issue of critical importance to the nation's future. To achieve this mission, the Center sponsors a wide variety of research projects, transmits new findings to a broad audience, trains new scholars, and broadens access to valuable data sources.

\author{
Center for Retirement Research at Boston College \\ Hovey House \\ 140 Commonwealth Avenue \\ Chestnut Hill, MA 02467 \\ phone: 617-552-1762 fax: 617-552-0191 \\ e-mail: crr@bc.edu \\ www.bc.edu/crr
}

\author{
Affiliated Institutions: \\ American Enterprise Institute \\ The Brookings Institution \\ Center for Strategic and International Studies \\ Massachusetts Institute of Technology \\ Syracuse University \\ Urban Institute
}




\begin{abstract}
Life-cycle funds offer an intuitive approach to retirement investing. Despite their intuitive appeal, the empirical and theoretical support for life-cycle funds is mixed. We examine life-cycle funds using dynamic optimization techniques to evaluate the optimal asset allocation over the life cycle. In our modeling we introduce a utility function that accounts for the individual's taste for bearing risk and analyze the role of human capital on allocation decisions. The simulations generally support the use of target retirement date funds once human capital is taken into account. Investment fees, however, could potentially erode any increased asset levels that life-cycle funds create. Ultimately, an appropriate asset allocation depends on individuals' objectives and the opportunities available in financial markets.
\end{abstract}




\section{Introduction}

Life-cycle funds, sometimes referred to as target retirement date funds, which gradually decrease stock holdings with age, offer an intuitive approach to retirement investing. Households are told that at younger ages "you have many years to withstand market volatility, so you can benefit from investing in a high percentage of stocks." ${ }^{\prime 1}$ In retirement, households are told that "your asset mix should now have a tilt towards income." Figure 1 shows the asset allocations of life-cycle funds of four major fund providers. All show a similar pattern, with equity asset allocations declining from 90 percent around age 30 to $25-35$ percent in retirement.

Figure 1. Percent in Equities for Selected Life-Cycle Funds, 2008

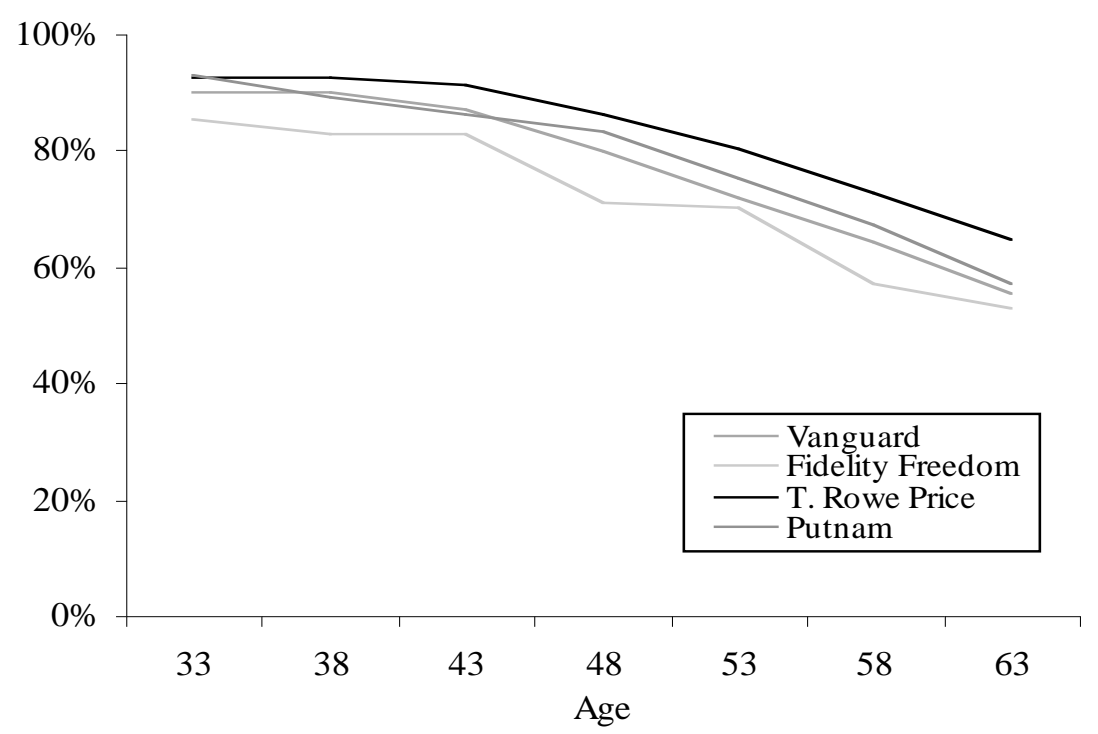

Source: Authors' calculations from Morningstar (2008).

This life-cycle strategy has considerable intuitive appeal. Although the return on stocks can be quite volatile in the short run, they outperform bonds in the long run. Accordingly, the traditional view has favored substantial investments in equity for young

\footnotetext{
${ }^{1}$ Vanguard Target Retirement 2050 summary www.vanguard.com. Other fund managers have similar messages.
} 
savers who could benefit most from the growth in wealth offered by the appreciation of stocks. As people enter retirement, this view counsels the shifting of wealth into bonds, because retirees have a greater need for the relatively stable income provided by bonds.

Despite their intuitive appeal, the empirical and theoretical support for lifecycle funds is mixed. Suitable allocations of assets do not depend solely on investors' ages. What matters most for investors is the total rate of return they realize on their investments and the risk they assume in earning this return. Attention to whether returns arise from capital gains or interest and dividends, rather than the total return, can lead to inefficient allocations of assets, wherein investors accept inadequate returns or earn too little return for the risks they are bearing. Investors, irrespective of age, should hold a mix of stocks, bonds, and short-term assets that achieves the best balance of expected return and risk for their specific needs and tastes.

Nevertheless, modern financial theory recognizes that life-cycle funds might still benefit investors for two important reasons. First, people hold a substantial portion of their wealth in human capital that is generally a low-risk asset whose return is largely uncorrelated with that of stocks. If it were optimal for investors to hold a constant share of their total wealth, inclusive of human capital, in stocks, then they should invest a large portion of their financial assets in stocks when they are young because at that point their financial assets are just a small portion of their total wealth. As they age, and their holdings of stocks eventually reach their optimal share of total assets, then they should begin investing their financial assets in a blend of stocks, bonds, and other securities. Second, people who anticipate purchasing income from annuities at retirement should consider shifting more of their assets into bonds as they approach retirement. This shift 
would hedge their risk of facing unfavorable annuity rates should interest rates fall abruptly as they retire. The value of their bonds would rise as interest rates fall, allowing them to purchase a greater volume of annuity income.

Ultimately, an appropriate asset allocation depends on individuals' objectives and the opportunities for achieving those objectives available in financial markets. Much of the appeal of stocks rests on their apparent ability to provide high long-run returns at relatively low risk. This attribute of stocks, emphasized in the personal finance literature (Malkiel 1991; Morrs, Spiegel, and Morris 1998; Quinn 1997), remains unproven. Not only is it possible for returns to fall below "normal" for long intervals, the "normal" return on stocks also varies substantially over time. Investors' optimal allocations of assets should respond to fundamental changes in the balance between the expected returns and risks offered by equities. Similarly, the relative appeal of stocks can change when new financial assets become available. The recent introduction of Treasury Inflation-Protected Securities (TIPS) allows many investors who otherwise would favor stocks to hedge the risk of rising inflation without having to hold stocks. Although some models of the asset allocation decision incorporate TIPS, they typically do so in ways that bias the results.

The remainder of the paper is organized as follows. In Section Two, we review the previous literature on optimal portfolio allocation over the life-cycle. In Section Three, we first present the results from our basic numerical optimization portfolio allocation model. Section Four presents evidence on the asset allocation of individuals and investment professionals. Section Five concludes. 


\section{Previous research}

There have been two main approaches to the analysis of asset allocation strategies. The first approach uses historical data to describe the performance of alternative strategies. This approach uses sequences of returns that are random draws from historical data. The performance of portfolios representing each allocation strategy is evaluated for each sequence of returns. Then, the allocations are ranked by the wealth (or utility) they generate over many simulations. The weakness of this approach is that it typically permits consideration of a few pre-determined strategies that may not include the optimal.

The second approach uses dynamic optimization techniques to evaluate the optimal asset allocation over the life cycle. This approach models the evolution of returns from historical data, which in principle allows the samples to diverge much more from previous experience, but in a way that reflects the historical structure asset returns.

Shiller (2006), which exemplifies the first approach, samples thirty-five year periods from historical data, assessing how various widely-advocated strategies for the allocation of assets would have performed over these intervals. Shiller's objective is not to estimate an optimal allocation but to show that life-cycle portfolios might be dominated by simple strategies.

Shiller examines six portfolios: three life-cycle portfolios with different levels of equity exposure (conservative, baseline, and aggressive); and three invariant portfolios (100 percent bonds, 100 percent equities, and 50-50 between stocks and bonds). Shiller finds that the all-stock strategy produces far superior returns over most points of the distribution of outcomes. Moreover, the worst return from an all-stock portfolio 
exceeded the worst returns from each of the alternatives considered. ${ }^{2}$ Shiller repeats the exercise, reducing the average real rate of return on equity to account for the possibility that the return on equity in the future might be less than that achieved in the past. The results are generally the same: the all-stock portfolio beating all other strategies even at the $10^{\text {th }}$ percentile. Shiller's objective, however, is not to estimate an optimal allocation but to highlight that life-cycle portfolios might be dominated by simple strategies.

Poterba et al. (2006) also take the historical Monte-Carlo approach. This alternative simply assumes that stocks and bonds will have returns drawn from an empirical distribution based on data from 1926 to 2002. They then draw from this distribution to simulate many sequences of returns for stocks and bonds. ${ }^{3}$ They conclude that an all-stock portfolio dominates the life-cycle allocation for all but the most risk averse individuals. But Poterba et al., like Shiller, do not estimate the optimal portfolio allocation, and they ignore the effects of management fees.

Cocco et al. (2005) exemplify the second approach, using a dynamic optimization approach to Monte-Carlo simulations using models of assets' returns. They account for non-tradable labor income and borrowing constraints, and they use numerical optimization to solve the asset allocation problem. Cocco et al. find that the presence of labor income increases the allocation of financial assets to stocks early in life.

\footnotetext{
${ }^{2}$ Although every point on the probability distribution of the outcomes of a 100 percent equities strategy exceeds the corresponding point for other strategies, without specifying the household's preferences, we can only be sure that an all stock strategy is preferred to other strategies if the former pays more than the later in each and every state of the world and it exhibits first order stochastic dominance.

${ }^{3}$ It is not clear whether Poterba et al. (2006) assumed that stock and bond returns were correlated.
} 


\section{Historical versus simulated returns}

For investors with long time horizons, investing in stocks has been a winning strategy. The superiority of stocks is confirmed by historical averages. The average real rate of return between 1871 and 2004 was 6.8 percent for stocks and 2.7 percent for bonds. Shiller (2006) finds that there in an extremely high probability that an all-stock allocation will yield a higher return than allocations that include bonds. But, Shiller's analysis, which considers only fixed allocations of assets, does not derive an optimal strategy for allocating assets, especially one that allows allocations to change over time.

We extend Shiller's analysis to derive the optimal investment strategy for an individual from age 30 to age 64, a 35-year interval. We use his data for the historical returns on stocks and bonds and estimate the optimal allocation by backward induction. At age 64, the individual chooses the optimal allocation of assets for the final year of his investment interval by considering the various combinations returns on stocks and bonds that might occur over one year. Stepping backward, to age 63, the individual next selects the optimal allocation for the first year of the two remaining years of his investment interval, given the optimal allocation for the second year that was selected in the first step. The individual continues this optimization process until age 31 .

According to this approach for optimizing returns, if people wish simply to maximize their expected wealth at age 65 , their optimal life-cycle allocation of assets includes only stocks (the top line in Figure 2). This finding is consistent with Shiller's results.

Individuals, however, typically consider the risk of their investments as well as their expected returns when they allocate their assets. By allocating all their assets to 
stocks, investors bear considerably more risk than they would by holding a mix of stocks and bonds. During 1871-2004, returns on stock had a standard deviation of about 17 percent and returns on long-term bonds had a standard deviation of 7 percent.

A simple extension of the model assumes that individuals maximize the ratio of the expected return on their assets to the standard deviation of this return. Using backward induction on all of the possible sequences available from historical data, we estimate the individual's optimal allocation of assets over his investment horizon, assuming at each step that he chooses the portfolio that maximizes his ratio of expected return to risk (the middle line in Figure 2). The exposure to stocks peaks at about 75 percent at age 40 and declines to 35 percent at age 64 . This optimal allocation calculated using past sequences of returns - reinforces the appeal of life-cycle portfolios.

Figure 2. Optimal Percent in Equities by Age, Historical and Simulated Data

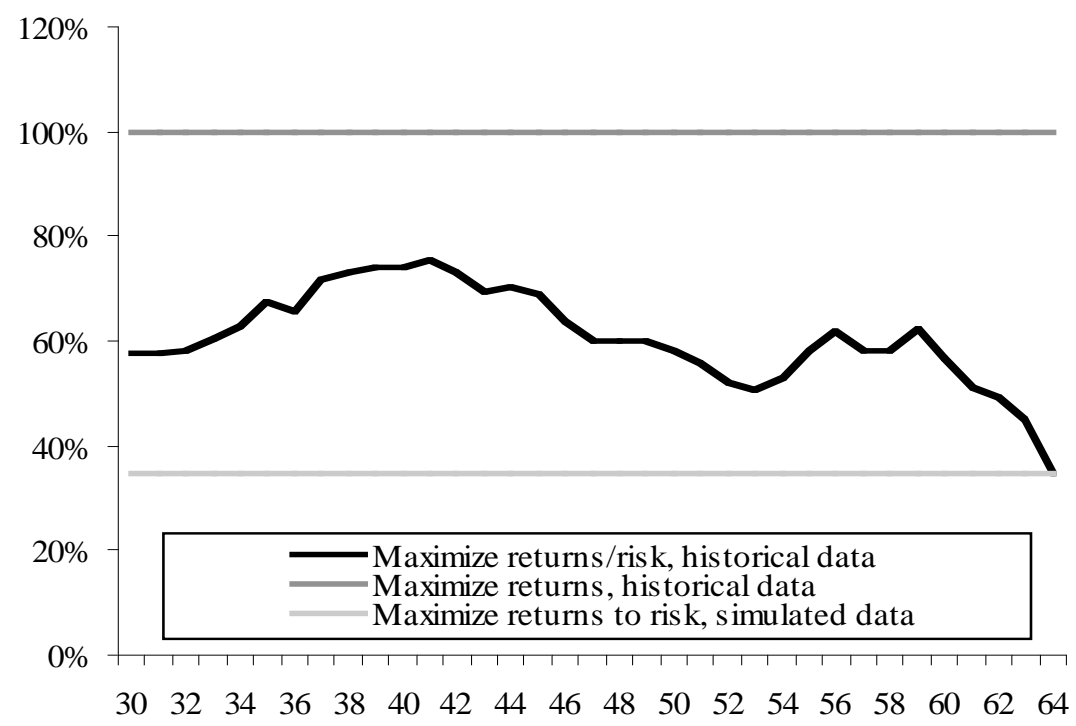

Source: Authors' calculations using data from Shiller (2008). 
But the results of this historical optimization might not be an appropriate guide for investors today, because returns in the future will not necessarily resemble those of the past. There are at least four reasons to think that past sequences of returns are not appropriate for describing potential results in the future.

First, we have at most 135 years of historical data - 135 sequences of one-year returns, 134 sequences of two-year returns, ..., and 100 sequences of 35-year returns. Because these sequences overlap to a substantial extent, they are not independent events. The sequences also will omit feasible adverse events that are so rare that they have yet to appear in the data, but which a prudent household might wish to take into account in its calculations. For example, investors could experience two Great Depressions in one lifetime or extended periods of hyper-inflation. From these simulations, it is not clear how including the possibility of occurrence of such events might affect the results for the various allocations of assets.

Second, the nature of the stock market has changed enormously over the past 135 years. In the late nineteenth century, it was dominated by railroads and utilities, and during much of the twentieth century the characteristics of capital market instruments continued to evolve. It is not clear how much can be inferred about the optimal allocation of household wealth in the twenty-first century from the performance of investments in the nineteenth and early twentieth century.

Third, the conduct of macroeconomic policy may have improved so that we are unlikely to experience a repetition of the Great Depression, which favored the performance of bonds relative to stocks, or the substantial inflation of the 1970s, which harmed bonds more than stocks. 
And fourth, economic conditions in the future can differ significantly from those in the past, thereby altering the fundamental returns investors might expect from various assets. In particular, the equity premium in the future will likely differ from that observed in the past. It is not for nothing that financial institutions warn that "past returns are no guide to future performance."

To address these issues, we simulate 10,000 paths of returns based on the historical means and standard deviations of the returns for stocks and long-term bonds. Individuals are assumed to maximize the ratio of expected returns to risk in their portfolios. Using backward induction on all of the possible sequences available from this simulated data, we estimate an optimal portfolio allocation (the bottom line in Figure 2). The resulting optimal allocation is flat at about 35 percent in stocks - nearly the same value as the age 64 allocation of the simulation that uses past sequences of returns (the last point of the middle line in Figure 2). The intuition behind the constant allocation throughout the life-cycle is that the optimal level of equity exposure for a one-year period should not be less than the exposure for a multi-year period when the distribution of returns are identical and independent from year to year. Assuming that bond and stock prices do not exhibit mean reversion, an allocation that is not optimal for a one-year horizon can not be optimal in a repeated sequence of years (Samuelson 1968; Merton 1969).

In summary, stocks have outperformed bonds over the last 135 years. An ex-post analysis shows that investing 100 percent in stocks would have produced the highest returns. If individuals care about risk, however, an ex-post analysis also suggests a strategy which gradually shifts assets from stocks to bonds with age would have 
generated the highest ratio of expected returns to risk. Therefore, we find justification for the life-cycle funds on an ex-post basis. But it is likely that the future sequence of returns do not resemble past sequences. Simulations of future returns suggest that the optimal allocation should not change over time. These results, however, are limited because they examine the allocation of financial assets without taking investors' labor income and willingness to bear risk into consideration.

\section{Introducing Expected Utility and Earnings}

In this section, we will extend the analysis by introducing a utility function that accounts for the individual's taste for bearing risk. We also analyze the role of human capital (in the form of earnings). These models of optimal portfolio allocation are not usually analytically tractable and must be solved numerically. This is computationally intensive, and often necessitates simplifying assumptions. Our approach begins with models that incorporate the common assumptions about the distribution of assets returns and about the choice of assets that appear in the existing literature. We assume individuals start saving for retirement at age 30 and retire at age 65 . Their goal is to maximize the expected utility of their retirement wealth. (See Appendix I for more details).

Baseline model. Our baseline model assumes that the household allocates its financial assets between stocks and long-term bonds. The mean and standard deviation of the real stock return is assumed to be 6.8 and 17 percent respectively; comparable figures for the real return on long-term bonds are 2.7 and 7.0 percent. We explicitly include a covariance between bond and stock returns, 0.26 percent, which matches the 
average over this period. Our approach searches over all possible allocations to find the optimal portfolio. We assume constant relative risk aversion, with coefficients of risk aversion of three, four, and five, to illustrate the effects of variation in taste for risk.

Figure 3 shows the results for the baseline model. This model assumes that individuals earn no wages between age 30 and age 65 . Instead, they are given a fixed amount of cash at age 30 which they decide how to allocate between stocks and bonds. The individual decides how to allocate her portfolio between stocks and bonds. Under this baseline model, the optimal portfolios vary little over the life-cycle - between 35 and 55 percent of assets are allocated to stock, depending on the risk tolerance of the individual. These results are consistent with the flat bottom line of Figure 2 - the optimal allocation for a one-year horizon is also optimal in a multi-year horizon — and suggest that a constant allocation to equity is preferable to life-cycle funds.

Figure 3. Optimal Percent in Equities by Age, Simulated Data without Earnings, by Coefficient of Risk Aversion

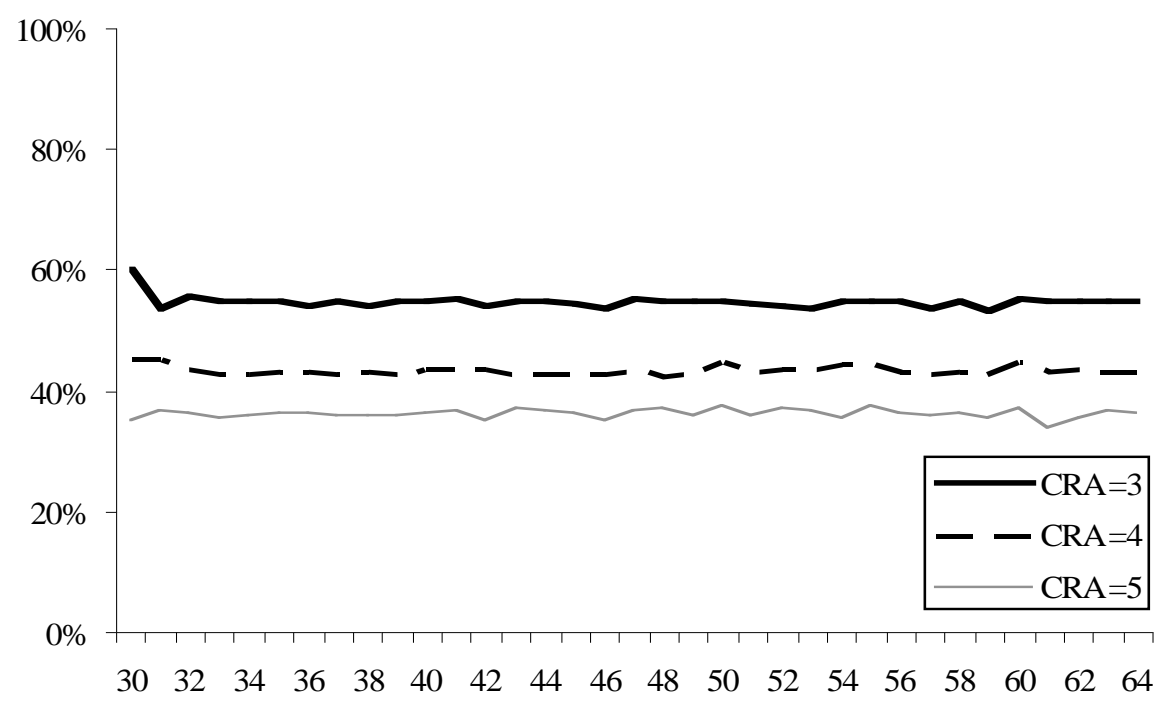

Source: Authors' calculations. 
Introducing Non-tradable Human Capital. The preceding simulations assume that individuals have no earnings. We introduce exogenous earnings using careerearnings profiles from the Office of the Actuary of the Social Security Administration (Clingman and Nichols 2004). ${ }^{4}$ This earning profile peaks at age 51 (in real terms). We assume that the individual saves 10 percent of his earnings each period. ${ }^{5}$ We also assume that individuals cannot borrow against their earnings — without this assumption, the optimal allocation would be similar to the one under no earnings.

With earnings, individuals allocate a substantial share of their assets to equity when they are young, their optimal allocation declines as they age (Figure 4). Individuals with a coefficient of risk aversion of 4 , for example, at age 30 hold about 65 percent of their retirement assets in equities; by age 40, they hold 50 percent in equities; and by age 64, they hold only about 45 percent in equities. The intuition behind declining exposure to equity over the life cycle is that earnings resemble their returns on bonds. Since human capital generates returns similar to those of bonds, it makes sense for young individuals to increase their allocation to stocks. As the value of their human capital

\footnotetext{
${ }^{4}$ Scaled factors determine the shape of the hypothetical wage profiles. To obtain these factors, Social Security uses a sample of workers with some OSADI taxable earnings during their lifetime, and restricts the analysis to those who are fully insured. Out of this sample, SSA focuses on the most recent 10 years of earnings, including years of zero earnings. To compute the scaled factors, SSA divides earnings for each individual by the Average Wage Index (AWI) for every year, and then groups the ratios by age. The resulting factor for the age group is the average of the individual observations. This methodology produces the age-specific raw scaled factors, which turn out to be less than 1 for each age and peak at age 48 (0.944). The next step is to adjust the raw scaled factors to make them consistent with the Average Indexed Monthly Earnings (AIME) derived for low, median, and high earners based on the steady earnings profiles used before 2001. (As a note, SSA moderates the scale factors for ages 62-64 because the original numbers showed a sharp rise at that age; instead it holds earnings constant in nominal terms from age 62 on.) The third step is to apply the modified scale factors to the AWI in each year to derive scaled earnings. The first set of published scaled factors used earnings data from 1988-97, but these factors are updated annually using the ten most recent years of data.

${ }^{5}$ The optimal allocations of financial wealth at the age the household commenced saving and at retirement do not depend on the age profile of earnings. But households with increasing earnings would save less when young and invest a greater proportion of those savings in stocks.
} 
depletes with age, individuals should shift their financial assets from stocks toward bonds.

Figure 4. Optimal Percent in Equities by Age, Simulated Data with Earnings, by Coefficient of Risk Aversion

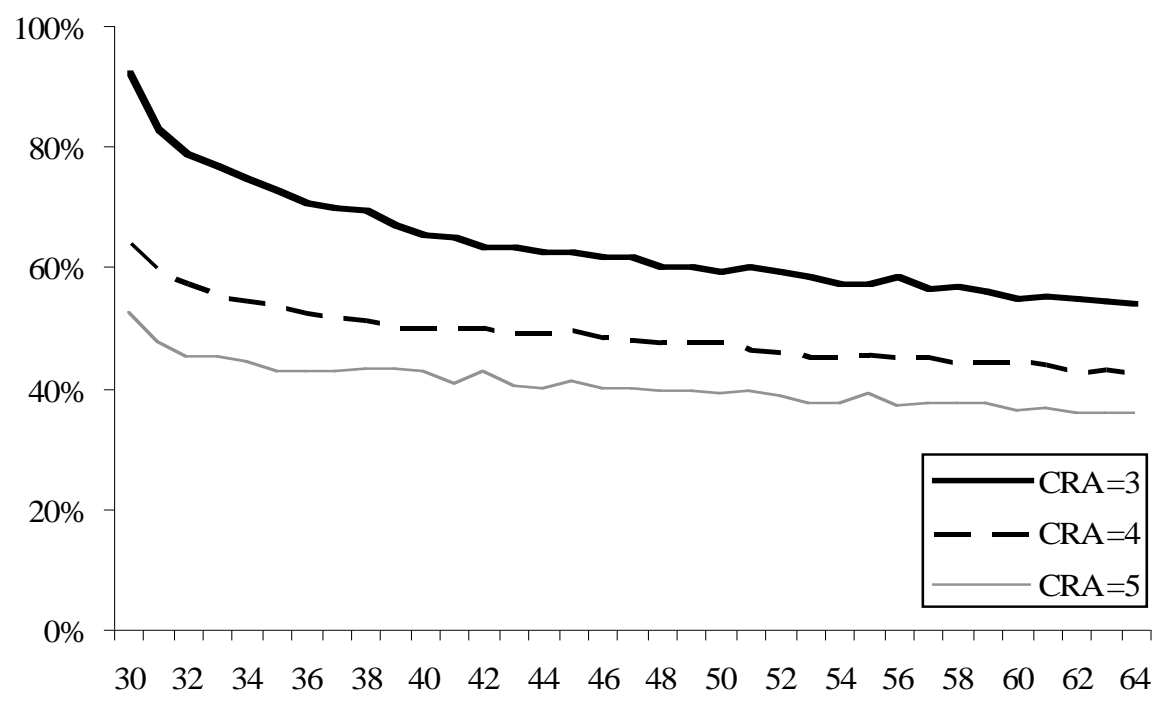

Source: Authors' calculations.

Introducing labor market uncertainty. The above simulations assume that the individual has no labor market uncertainty. In practice, individuals experience employment shocks, the effects of which can be quite persistent. The degree of correlation between these shocks and the returns on stocks and bonds will vary from individual to individual. At retirement, human capital is exhausted, and for any given proportion of financial to total wealth, the optimal allocation of financial wealth will depend solely on the means, variances, and covariances of stock and bond returns and the household's degree of risk-aversion. Prior to retirement, individuals with risky human capital will invest a smaller proportion of financial wealth in stocks than those with riskfree human capital. In the extreme, individuals whose human capital is as risky as stocks 
would invest very little of their financial assets in stocks when they are young and increase the proportion of financial wealth invested in stocks as they age and the value of their human capital declines.

We consider a simple model that describes labor market uncertainty. In particular, we ignore the possibility that households might save for precautionary reasons and might wish to hold such savings in a relatively liquid form. ${ }^{6}$ We assume that earnings follow the same hump-shaped earnings profile, but each year these earnings deviate from the profile by a percent determined by stock market returns.

Figure 5 shows the results for an individual with a coefficient of risk aversion of four. For individuals with no correlation or with a positive correlation between earnings and returns on stock, the allocation offered by life-cycle funds - declining exposure to stocks over time - seems appropriate. But individuals with earnings correlated with stocks should follow the opposite strategy, holding more bonds when young and gradually shifting their financial assets into stocks as they age.

There has been a great deal of scholarship exploring the correlation between labor income and stock returns and attempting to quantify its importance. Cocco et al (2005) examined the correlation between permanent and transitory labor income shocks and stock returns for workers with different education levels. Heaton and Lucas (2000) assert that, although wage income is correlated to stock returns, proprietary income has a stronger correlation. When examining what effects the correlation between labor earning and stock returns have on portfolio choice, Viceira (2001) has found that the existence of

\footnotetext{
${ }^{6}$ The precautionary savings literature, for example Hubbard, Skinner, and Zeldes (1995) does not discriminate between classes of financial assets. Although financial planners often recommend that households invest precautionary savings in bank deposits, there seems little reason not to hold them in stocks, which are almost as liquid.
} 
risky earnings increases the optimal allocation to stocks. Some, however, have doubts about the cause of variance in labor income. Fama and Schwert (1977) found that labor income showed little short-term relationship with either expected or unexpected inflation, and did not believe it had an effect on hedging against poor stock returns ${ }^{7}$.

Figure 5. Optimal Percent in Equities by Age, Simulated Data with Earnings, Individuals with a Coefficient of Risk Aversion Equal to 4.

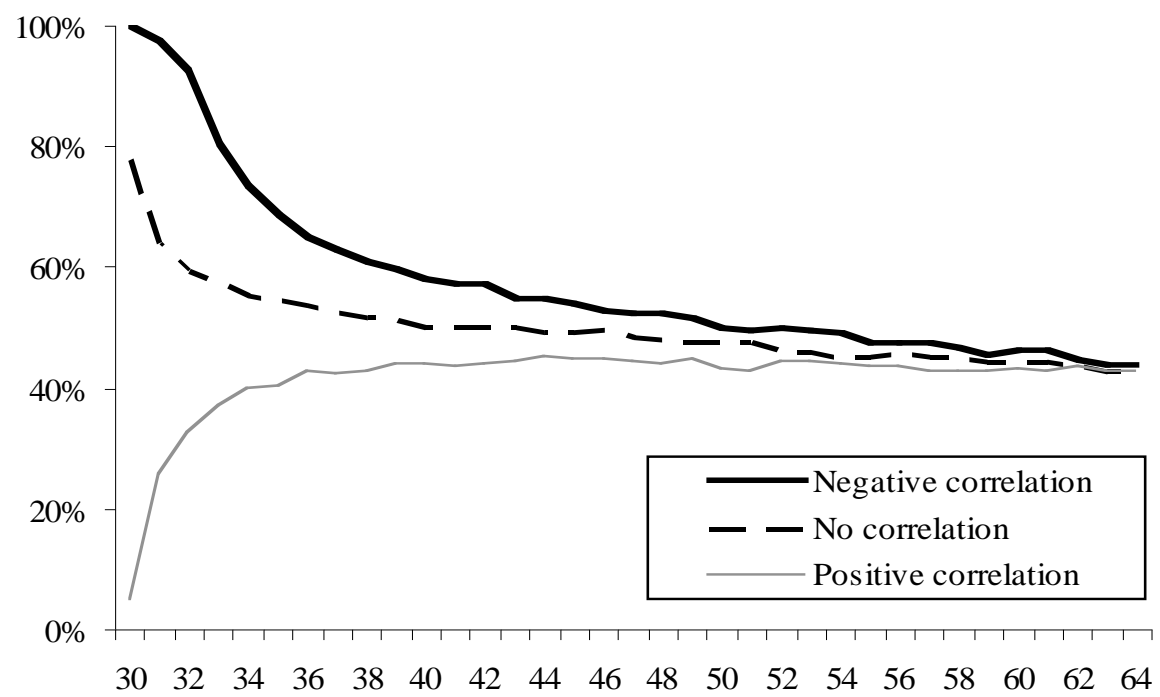

Source: Authors' calculations.

Decreased equity returns. Many economists believe that there has recently been a narrowing of the equity and, to a lesser extent, the bond risk premiums. Shiller (2006) reports a survey of the expectations of professional economists. The mean expected equity and bond returns over the 44 years from 2005 are 4.6 and 2.9 percent respectively. ${ }^{8}$ We repeat our analysis assuming the same standard deviation as before, but incorporating these lower expected returns. As might be expected, the gains from

\footnotetext{
${ }^{7}$ Although the popular sentiment is that labor income is indeed correlated to stock returns, the magnitude and direction will most definitely vary throughout industries. In our research, we have not found any clear measure that would accurately quantify this correlation across the population. We assume that any correlation that does exist will be relatively small for the average individual.

${ }^{8}$ Assuming a 50:50 allocation between government and corporate bonds.
} 
holding an all-equity portfolio diminish, but the shape of the optimal allocation remains (see Figure 6).

Figure 6. Optimal Percent in Equities by Age, Simulated Data with Earnings and Lower Projected Stock Returns, by Coefficient of Risk Aversion

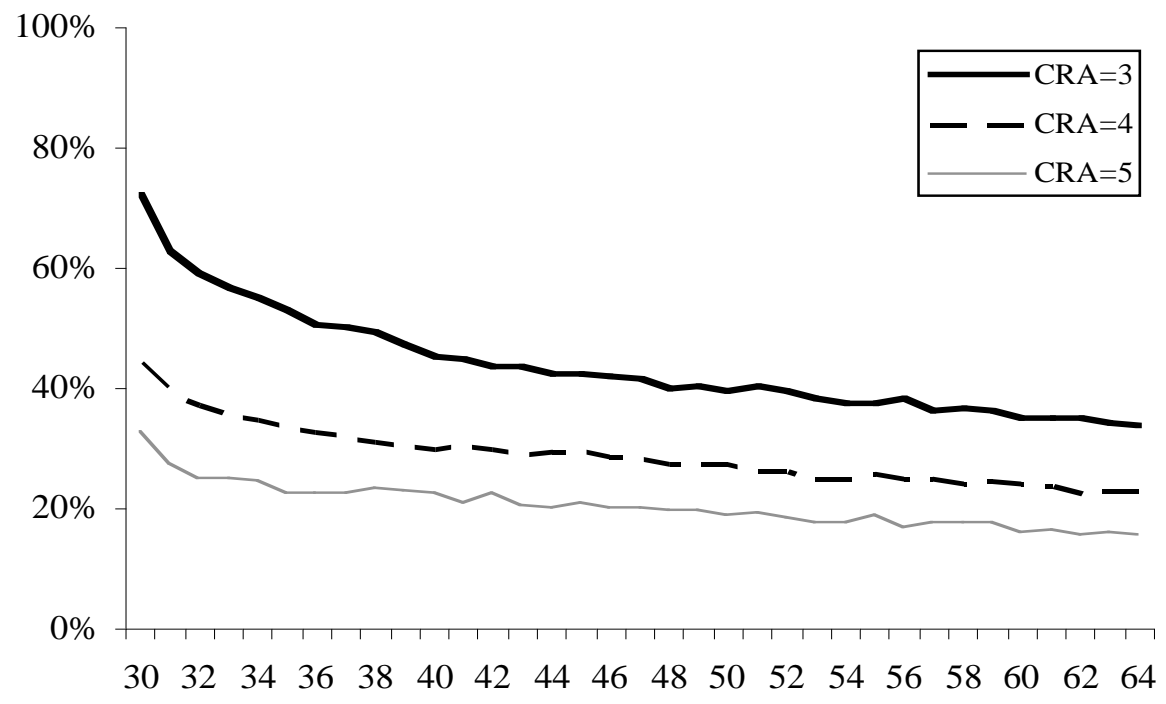

Source: Authors' calculations.

Mean Reversion. Despite considerable research, the question of whether bond and stock returns exhibit mean reversion remains controversial. Under the commonly used assumption that stock and bond returns are i.i.d., the optimal investment allocation does not vary with time horizon. While it is true that the probability of a stock outperforming a bond portfolio increases with the holding period, this is precisely offset by the increased probability of obtaining exceptionally poor returns.

But the optimal allocation may vary with time horizon if stock and bond returns exhibit mean reversion. But as Campbell and Viceira (2002) point out, if stocks exhibit mean reversion, future stock returns will, to some extent, be forecastable, and optimal investment allocation will also depend on whether stocks are cheap or expensive relative to their long run average. But it will also depend on the attractiveness of bonds, which in 
turn will depend on the current and anticipated term structure of nominal and real interest rates. As far as we are aware, no life-cycle fund explicitly claims to adjust portfolio allocations on the basis of both age and anticipated excess returns.

The Role of Fees. The simulations above generally support the use of target retirement date funds once human capital is taken into account. These funds, however, might come with a high price tag for individuals. Table 1 shows the expense ratio associated with popular life-cycle funds. These expenses are sometimes considerably higher than the expenses of index funds which can be as low as 10 basis points. The exception is Vanguard with an expense ratio of only 20 basis points.

Table 1. Expense Ratios of Target Retirement Date Funds

\begin{tabular}{|c|c|c|c|c|}
\hline & Vanguard & Fidelity & T Row Price & Putnam \\
\hline $\begin{array}{c}\text { Average } \\
\text { Expense ratio }\end{array}$ & $0.20 \%$ & 0.77 & $0.69 \%$ & $1.19 \%$ \\
\hline
\end{tabular}

Authors' calculations from Morningstar (2008).

The question is whether life-cycle fund strategies are optimal after accounting for these fees. To examine this question, we estimate the expense ratio that would make individuals indifferent — in terms of utility — between following a flat asset allocation strategy (Figure 3) and following a declining equity exposure strategy (Figure 4). The results are shown in Figure 7. The message is that the possible gains from using a lifecycle portfolio can be easily offset by increases in expense ratio. The simulations suggest that if life-cycle funds increase the expense ratios paid by individuals by more than 20 basis points, individuals would be better off following a flat equity allocation throughout their life. 
Figure 7. Expense Ratio that Would Make Individuals Indifferent between a Flat Asset Allocation and a Target Fund Allocation, by Coefficient of Risk Aversion

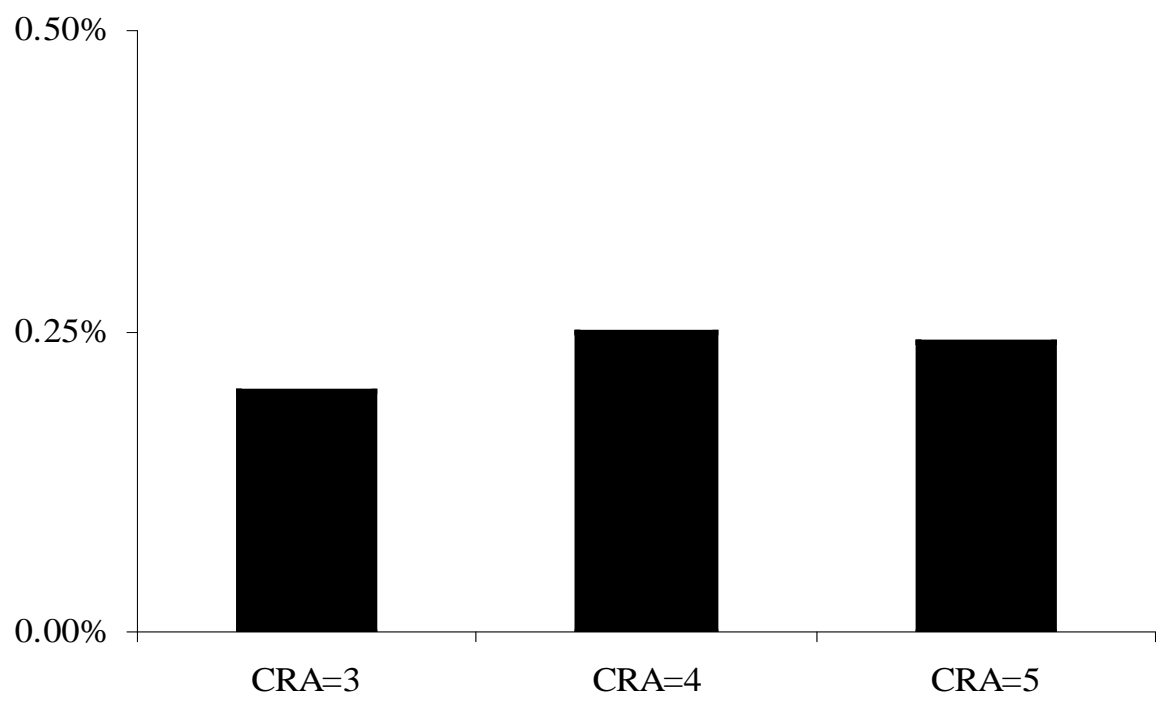

Source: Authors' calculations.

The simulation results can be summarized as follows. The optimal portfolio allocation for an individual with a coefficient of risk aversion of four is about 45 percent in equities and 55 percent in bonds. This is true for the total wealth of the individual. When part of the wealth is in human capital — in the form of future earnings, individuals should start with high equity exposure (about 65 percent of their financial wealth) and gradually reduce the percent in equities in their portfolio to about 45 percent. A higher (lower) degree of risk aversion produces similar patterns with lower (higher) exposure to stocks. The declining exposure to stocks over time depends on the correlation of earnings and stock returns (individuals with positive correlation between their earnings and stock returns should follow the opposite strategy.) The expected decline in the equity premium is likely to change the level but not the shape of the 
optimal portfolios. If the expected return of stocks were 2 percentage points lower than the historical average, optimal portfolio allocation should include about 20 percent less in stocks. Finally, fees are important when popular life-cycle funds. The simulations suggest that an increase in fees of more than 20 basis point could wipe out the potential gains these funds relative to a portfolio that maintain a constant equity allocation over the life-cycle.

\section{Asset Allocation of Individuals and Investment Professionals}

In this section, we analyze whether individuals and investment professionals are following the asset allocation patterns suggested by life-cycle funds. For individuals, we use data from the Survey of Consumer Finances (SCF) between 1989 and 2004. For investment professionals, we use data on defined benefit pension funds from the 5500 Filings between 1989 and 2004.

Evidence from the SCF. The SCF includes information about the asset allocation of retirement accounts. The question is whether there exist a relationship between the age of the household and the percent in equities in their retirement portfolios. For simplicity, we exclude other financial assets and focus on households headed by an individual age 30 to age 64 .

Figure 8 shows the asset allocation by age for the different cross-sectional observations. At any point in time, younger households generally hold more equities in their retirement accounts than older households. In fact, during the period 1989-2004, the average household age 30-34 held about 55 percent of their retirement portfolio in stocks compared to 48 percent for in the portfolio of households 60-64. The decline in equity 
exposure, however, is much less steep than the decline suggested by the simulations in the previous section.

Figure 8. Percent in Equities in Retirement Accounts for Different Survey Years, by Age, 1989-2004.

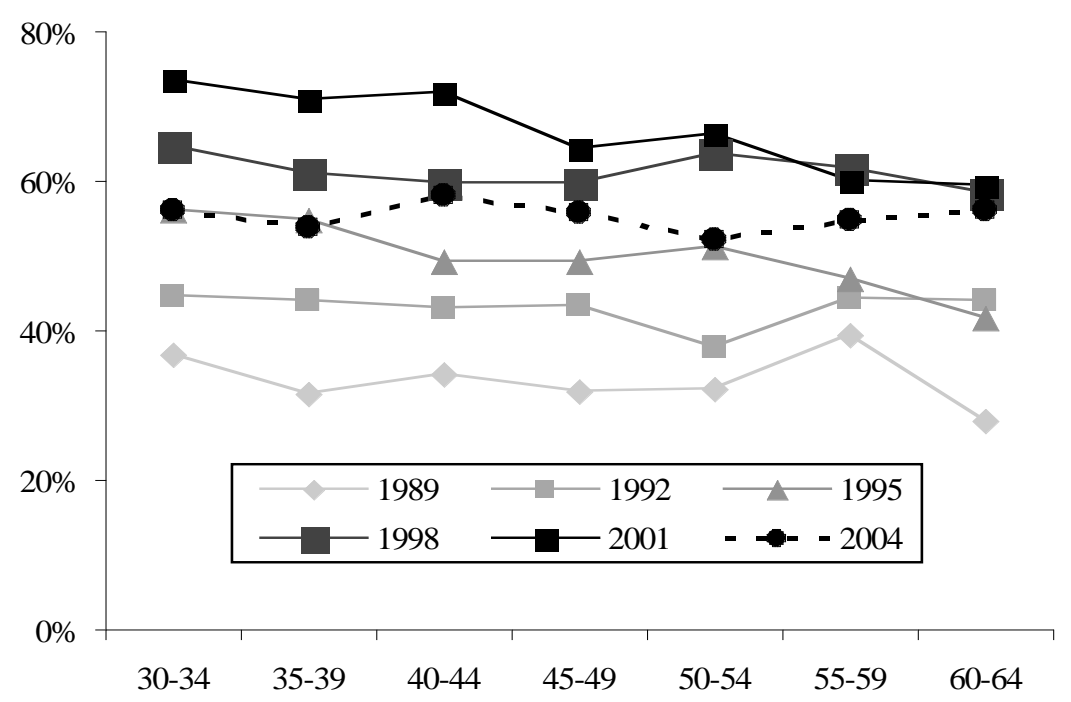

Source: Authors' calculations.

There are questions, however, on whether these results mean that households move slowly away from stocks as they age (for a review of this literature, see Ameriks and Zeldes 2004). The main reason is that different interpretations of the data result from accounting for cohort or year (time) effects. Ignoring year effects, for example, it is possible to show an increasing exposure to stocks over the life cycle. Following each cohort over time suggests that the household holds a larger portion of their retirement assets in equities as they age — opposite to the life-cycle fund prescription (Figure 9). 
Figure 9. Percent in Equities in Retirement Accounts for Different Cohorts, by Age, 1989-2004.

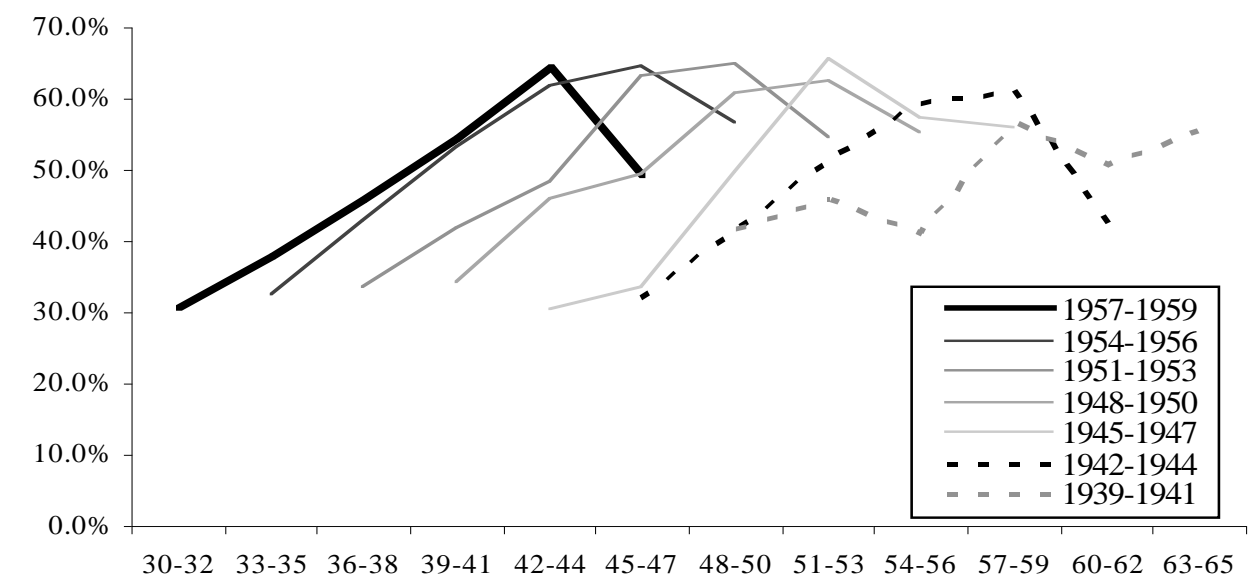

Source: Authors' calculations.

In sum, the evidence from the SCF suggests that households are, at best,

following a relatively flat asset allocation over the life cycle. Analysis of data on households is limited because it is nearly impossible to separate year and cohort effects from the analysis without making further assumptions.

Evidence from Investment Professionals. We examine whether the asset allocation of pension funds depend on the age profile of the pension beneficiaries. The notion is that pension plans, in some ways, face the same optimization problem that individuals face when financing their retirement accounts: plan sponsors make periodic contributions to an investment portfolio intended to fund future benefits. Data on asset allocation of pension plans have two advantages over household survey data. First, the asset allocation decision in pension funds is generally made by investment managers who are likely to be more financially savvy than individuals. Understanding how investment professionals invest their assets over the life of the pension plan serves as a guide for how individuals ought to allocate their assets in their retirement accounts over their working life. The 
second advantage is technical. Data on pension plans does not have the limitations imposed by the cohort and year effects in household survey data.

We use data on pension plans from filings of the Form 5500 between 1989 and 2004. ${ }^{9}$ We limit the analysis to private defined benefit plans with more than 100 participants. For the age of the plan, we use the ratio of retirees to total participants - a young plan should have a low ratio; an old plan should have a high ratio. Figure 10 shows the average percent of stocks held in these pension funds during the period 19892004 and the average age of the plan. Defined benefit plans are getting older: the proportion of retirees to participants went from about 30 percent in 1989 to nearly 50 percent in 2004. But as these plans grew older, they invested a larger part of their portfolio in stocks - contrary to the life-cycle funds prescription.

Figure 9. Percent in Equities and Ratio of Retirees to Total Participants in Defined Benefit Plans, 1989-2004.

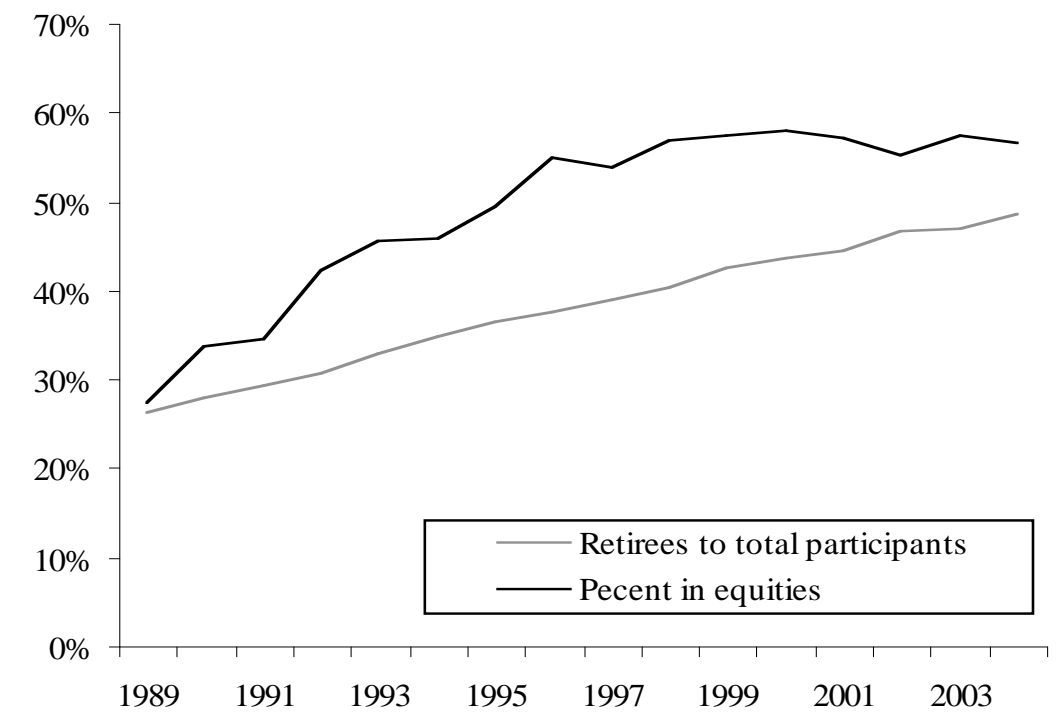

Source: Authors' calculations.

\footnotetext{
${ }^{9}$ For more details on these data, see Buessing and Soto (2006).
} 
It is possible, however, that the increase in exposure to equities was more of response to secular trends than a strategic move in response to the aging of the plan. Since 1980, shifts in the investment strategies of institutional and individual investors have principally reflected changing opportunities in capital markets. Between 1982 and 1994, the yield on US Treasury notes fell from just over 14 percent to 6 percent. During this interval mutual funds and closed-end funds invested heavily in bonds. Mutual funds' share of total assets held in bonds rose from 30 percent to 60 percent; closed-end funds' share rose from 40 percent to nearly 80 percent. At the same time, the allocation of assets to bonds remained near 35 percent for both defined-benefit and defined-contribution pension plans. After 1994, bonds became less appealing as the trend toward lower interest rates broke, and the yield on Treasury notes largely varied between 4 percent and 6 percent. At the same time, the strong growth of corporate profits made equities more appealing. Bonds' share of assets in mutual funds and closed-end funds fell substantially to 30 percent and 20 percent respectively. For defined-benefit and defined-contribution pension plans, bonds' share fell below 20 percent.

In order to separate these secular trends from the aging of the plan, we run a fixed-effect regression with the percent of assets in stocks as the dependent variable. We use year dummies to control for the aggregate trends. The fixed-effect specification controls for any firm specific characteristic — such as industry or taste for risk. For the age of the plan, we use dummy variables based on the ratio of retirees to total participants. Figure 10 shows the coefficients of the age of the plan dummies from this regression (the full results are reported in Appendix II). The coefficients suggest a declining proportion of the portfolio as the ratio of retirees to total participants increase. 
All of the coefficients are statistically significant. The pace of the reduction, however, seems too slow relative to the simulations. For example, the coefficients imply that a young plan with ratio of only 10-20 percent of retirees to total participants should have an additional 3 percentage points of their portfolio in stocks relative to an old plan with a retirees to participant ratio of nearly 100 percent.

Figure 9. Effect of the Ratio of Retirees to Total Participants on the Percent of Stocks in the Pension Fund Portfolio, Defined Benefit Plans, 1989-2004.

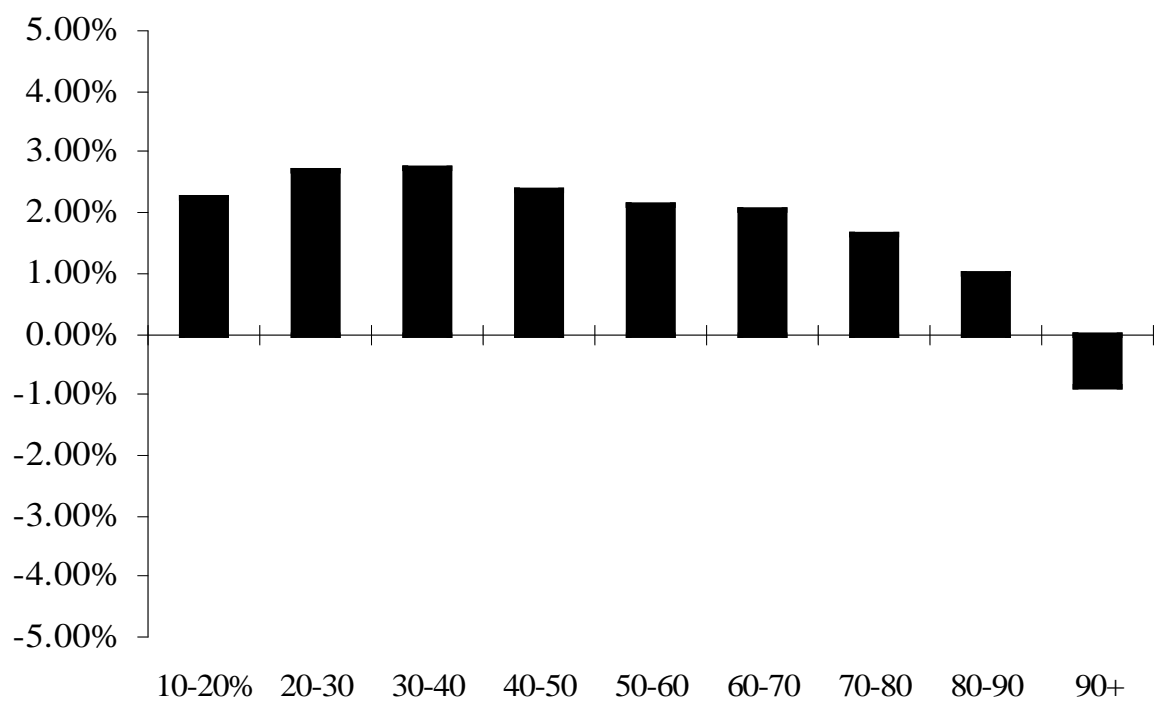

Source: Authors' calculations.

Note: The dummy for a ratio of retirees to participant equal to less than 10 is the omitted variable.

In sum, the evidence does not seem to suggest a strong decline in the portfolio exposure to stocks over the life cycle. For individuals, evidence from the SCF suggests, at best, a small decline over the life cycle. Data from pension plans suggests that the shift away from stocks over the life of pension plans is much less marked than a typical lifecycle fund — or the simulations — would suggest. 


\section{Conclusion}

Life-cycle funds offer an intuitive approach to retirement investing. Households that are younger have many years to withstand market volatility, so you can benefit from investing with a higher allocation to stocks. In retirement, households should mix assets so that they have a tilt towards income. Despite their intuitive appeal, the empirical and theoretical support for life-cycle funds is mixed. Ultimately, an appropriate asset allocation depends on individuals' objectives and the opportunities for achieving those objectives available in financial markets.

There are two approaches to evaluating optimal asset allocation. The first uses historical data to describe the performance of alternative strategies. The second uses dynamic optimization techniques to evaluate the optimal asset allocation over the life cycle. According to the first approach for optimizing returns, if people wish simply to maximize their expected wealth at age 65 , their optimal life-cycle allocation of assets will consist only of stocks (the top line in Figure 2). Individuals, however, typically consider the risk of their investments as well as their expected returns when they allocate their assets. By allocating all their assets to stocks, investors bear considerably more risk than they would by holding a mix of stocks and bonds. Dynamic optimization allows risk to be considered in the optimal allocation decision.

There are dangers in using historical data to understand allocation optimization. It must be noted that returns in the future will not necessarily resemble those of the past. The nature of the stock market has changed enormously. In the late nineteenth century, it was dominated by railroads and utilities, and during much of the twentieth century the characteristics of capital market instruments continued to evolve. Also, the conduct of 
macroeconomic policy may have improved so that we are unlikely to experience a repetition of the Great Depression, which favored the performance of bonds relative to stocks, or the substantial inflation of the 1970s, which harmed bonds more than stocks. In our modeling, we extend the analysis by introducing a utility function that accounts for the individual's taste for bearing risk. We also analyze the role of human capital (in the form of earnings). Our baseline model assumed that the household allocates its financial assets between stocks and long-term bonds. Under this baseline model, the optimal portfolios vary little over the life cycle — between 35 and 55 percent of assets are allocated to stock, depending on the risk tolerance of the individual (Figure 3). We introduce exogenous earnings using career-earnings profiles. With earnings, individuals allocate a substantial share of their assets to equity when they are young, their optimal allocation declines as they age (Figure 4). The simulations generally support the use of target retirement date funds once human capital is taken into account. Investment fees, however, could potentially erode any increased asset levels that life-cycle funds create.

By using the SCF, we were able to analyze whether individuals and investment professionals are following the asset allocation patters suggested by life-cycle funds. The evidence from the SCF suggests that households are, at best, following a relatively flat asset allocation over the life cycle while investment professionals managing DB plans invested a larger part of their portfolio in stocks — contrary to the life-cycle funds prescription. It is possible, however, that the increase in exposure to equities was more of response to secular trends than a strategic move in response to the aging of the plan. In 
sum, the evidence does not seem to suggest a strong decline in the portfolio exposure to stocks over the life cycle. 


\section{References}

Ameriks, John, and Stephen Zeldes. 2004. "How do Household Portfolio Shares Vary With Age?" Working Paper. New York, NY: TIAA-CREF.

Campbell, John Y. and Luis M. Viceira. 2002. "Is the Stock Market Safer for LongTerm Investors?" In Strategic Asset Allocation. Oxford University Press: Oxford, England.

Clingman, Michael and Orlo Nichols. 2004. "Scaled Factors for Hypothetical Earnings Examples under the 2004 Trustees Report Assumptions." Actuarial Note, 2004.3. Office of the Chief Actuary, Social Security Administration.

Cocco, Joao F., Fancisco J. Gomes, and Pascal J. Maenhout. 2005. "Consumption and Portfolio Choice over the Life Cycle." The Review of Financial Studies 18(2): 491-533.

Malkiel, Burton M.1991. A Random Walk Down Wall Street. New York: Norton Publishing.

Merton, Robert C. 1969. "Lifetime Portfolio Selection Under Uncertainty: The Continuous Time Case." The Review of Economics and Statistics 51(3):247-257.

Morningstar. 2008. "Expense Ratio Data.” Available at: www.Morningstar.com.

Poterba, James, Joshua Rauh, Steven Venti, and David Wise. 2006. "Life-cycle Asset Allocation Strategies and the Distribution of 401(k) Retirement Wealth." Working Paper 11974. Cambridge, MA: National Bureau of Economic Research.

Quinn, Joseph F. 1997. "Retirement Trends and Patterns in the 1990s: The End of an Era?" Working Paper 385. Chestnut Hill, MA: Boston College Department of Economics.

Samuelson, Paul A. 1969. "Lifetime Portfolio Selection by Dynamic Stochastic Programming." The Review of Economics and Statistics. 51: 239-246.

Siegel, Alan M., Kenneth Morris, and Virginia B. Morris. 1998. “The Wall Street Journal Guide to Planning Your Financial Future." Simon and Schuster.

Shiller, Robert J. 2006. "The Life-Cycle Personal Accounts Proposal for Social Security: An Evaluation of President Bush's Proposal." Journal of Policy Modeling (28):427-444. 
Shiller, Robert J. 2008. "An Update of Data Shown in Chapter 26 of Market Volatility, R. Shiller, MIT Press, 1989, and Irrational Exuberance, Princeton 2005.” Available at: http://www.econ.yale.edu/ shiller/data/chapt26.xls. 


\section{Appendix I}

The Model. The optimal asset allocation algorithm begins with several assumptions. There are $i$ adult individuals each investing over the course of a course of time of length $T$. Also, these investors are risk averse. For simplicity $T$ is assumed to be exogenous and deterministic. We assume that there are two assets, stocks and bonds, which have normally distributed real returns around historical means. The returns of the two assets have a covariance and a corresponding probability matrix. For each period $t$, stock and bond returns will be denoted as $s_{i t}$ and $b_{i t}$ respectively. The returns are said to be independently and identically distributed (i.i.d.) over time. In addition to receiving returns on investments, each year the investor increases his asset value by adding labor earnings, $Y_{t}$, which is an exogenously given value ${ }^{10}$. The expected value of utility provided by a portfolio at time $t, E U_{t}$, is given by the function,

$$
E U_{t}=\sum_{t}^{T} P_{t} \frac{W_{t}^{(1-\delta)}}{(1-\delta)}
$$

where $W_{t}$ is the wealth of the portfolio at time $t, P_{t}$ is the probability of having $W_{t}$ at time $t$, and $\delta$ is the level of relative risk aversion. Before retirement, labor income, $Y_{i t}$, is exogenously set at each period using career earning profiles from the Office of the Actuary of Social Security.

In each period $t$, the timing of the events is as follows. An investor starts the period with wealth $W_{i t}$. Then labor income is realized. Following Deaton (1991) we

\footnotetext{
${ }^{10}$ The earnings profile follows lifetime career-earning profiles from the Office of the Actuary of the Social Security Administration (Clingman and Nichols 2004).
} 
denote total assets-on-hand for period $t$ as $X_{i t}=W_{i t}+Y_{i t}$. The next period's wealth is denoted as:

$$
W_{i, t+1}=R_{i, t+1}^{P}\left(W_{i t}+Y_{i t}\right)
$$

where $R_{i, t+1}^{P}$ is the total return on the portfolio for period $t+1$ :

$$
R_{i, t+1}^{P}=(\alpha)\left(s_{i, t+1}\right)+(1-\alpha)\left(b_{i, t+1}\right) .
$$

We assume that the individual is unable to borrow against future earnings and allocations to stock are non-negative (short-sales of equities is not allowed). The problem the investor faces is to maximize expected utility subject to the constraints and assumptions listed above. The control variables are $\left\{\alpha_{i t}\right\}_{t=1}^{T}$ and the state variables are $\left\{t, X_{i t}, v_{i t}\right\}_{t=1}^{T}$, where $v_{i t}$ is an i.i.d. temporary shock that determines stock and bond returns. The expected future value of utility is discounted at a rate of $\beta$ for each period.

The Bellman equation used to solve this problem is:

$$
V_{i t}\left(X_{i t}\right)=\underset{0 \leq \alpha_{i t} \leq 1}{\operatorname{Max}}\left[U\left(W_{i t}\right)+E_{t} V_{i, t+1}\left(X_{i, t+1}\right)\right] \text { for } t<T
$$

where,

$$
X_{i, t+1}=Y_{i, t+1}+\left(X_{i, t+1}\right)\left(\alpha s_{i, t+1}+(1-\alpha) b_{i, t+1}\right) \text {. }
$$

This problem cannot be solved analytically. Therefore the policy functions are derived numerically using backwards induction. The policy functions of the last period are trivial (the investor consumes all wealth) and the value function corresponds to the utility function. We can substitute value functions into the Bellman equation and calculate allocation choices for the previous period. We optimize by interpolating to a discrete 
space grid for the continuous state variable $X_{i t}$. Given the allocation choices, we can obtain the value functions and this process is iterated back until we reach time $t=1$.

The returns on the two assets were approximated following Tauchen and Hussey (1991) using Gaussian quadrature methods. The possible values fell within four standard deviations centered at historical mean returns for stocks and bonds. In order to avoid numerical convergence, we optimized over the space of the decision variables using a simple grid search. The sets of admissible values for the decision variable (portfolio allocation), was discredited using equally spaced grids and intervals of 2.5 percent. The state-space was also discredited. Because the range between the smallest and largest possible asset values for a period became extremely large (and also highly improbable), we were forced to distribute the discredited asset values for the grid in a more plausible fashion ${ }^{11}$. Because of the assumption that savings is non-negative, the lower-bound on the asset level grid is strictly positive. During backwards induction, in order to evaluate the value function for asset values that do lie in the grid of discrete values, we used a nearest neighbor interpolation in the $\log$ of the state variable to find values within the grid.

Using optimal allocation choices for each asset level at period $t$, we ran 1000 simulations in order to find a median allocation decision, asset level and utility at each period. In addition to changing the level of relative risk aversion, we investigated whether

\footnotetext{
${ }^{11}$ We ran 1000 portfolio trials to find a more accurate distribution of the asset levels reached in each period. Grid points were equally spaced according to the following measures: 10 percent equally spaced between the minimum asset level and the $10^{\text {th }}$ percentile, 15 percent equally spaced between the $10^{\text {th }}$ and $25^{\text {th }}$ percentiles, 50 percent equally spaced between the $25^{\text {th }}$ and $75^{\text {th }}$ percentiles, 15 percent equally spaced between the $75^{\text {th }}$ and $90^{\text {th }}$ percentiles, and 10 percent equally spaced between the $90^{\text {th }}$ percentiles and the maximum asset level.
} 
the earnings prescribed by the wage profile were positively correlated, negatively

correlate, or uncorrelated affected the allocation choices of the investor.

\section{Appendix II}

\section{Fixed-Effects Regression Results}

Dependent variable: Percent in Equities

\begin{tabular}{|l|r|r|}
\hline \multicolumn{1}{|c|}{ Variable } & Coefficient & SE \\
\hline Ratio of retirees to total participants 10-20 & 0.0223 & 0.0020 \\
\hline Ratio of retirees to total participants 20-30 & 0.0270 & 0.0021 \\
\hline Ratio of retirees to total participants 30-40 & 0.0271 & 0.0022 \\
\hline Ratio of retirees to total participants 40-50 & 0.0236 & 0.0024 \\
\hline Ratio of retirees to total participants 50-60 & 0.0211 & 0.0026 \\
\hline Ratio of retirees to total participants 60-70 & 0.0206 & 0.0030 \\
\hline Ratio of retirees to total participants 70-80 & 0.0164 & 0.0036 \\
\hline Ratio of retirees to total participants 80-90 & 0.0099 & 0.0047 \\
\hline Ratio of retirees to total participants 90-100 & -0.0085 & 0.0035 \\
\hline Year 1990 & 0.1399 & 0.0020 \\
\hline Year 1991 & 0.1451 & 0.0021 \\
\hline Year 1992 & 0.2067 & 0.0022 \\
\hline Year 1993 & 0.2272 & 0.0022 \\
\hline Year 1994 & 0.2315 & 0.0022 \\
\hline Year 1995 & 0.2564 & 0.0023 \\
\hline Year 1996 & 0.2948 & 0.0024 \\
\hline Year 1997 & 0.3088 & 0.0024 \\
\hline Year 1998 & 0.3301 & 0.0025 \\
\hline Year 1999 & 0.3468 & 0.0025 \\
\hline Year 2000 & 0.3442 & 0.0025 \\
\hline Year 2001 & 0.3447 & 0.0026 \\
\hline Year 2002 & 0.3287 & 0.0026 \\
\hline Year 2003 & 0.3608 & 0.0027 \\
\hline Year 2004 & 0.3538 & 0.0027 \\
\hline Year 2005 & 0.3598 & 0.0031 \\
\hline Constant & 0.1062 & 0.0024 \\
\hline & & \\
\hline R2 & & 0.30 \\
\hline Number of observation & & 208,145 \\
\hline Number of plans & & \\
\hline Source: A & & \\
\hline
\end{tabular}

Source: Authors' calculations. 


\section{RECENT WORKING PAPERS FROM THE}

\section{CENTER FOR RETIREMENT RESEARCH AT BOSTON COLLEGE}

Participant Perceptions and Decision-Making Concerning Retirement Benefits Colleen E. Medill, February 2008

A Micro-Level Analysis of Recent Increases in Labor Participation Among Older Workers

Kevin E. Cahill, Michael D. Giandrea, and Joseph F. Quinn, February 2008

The Trajectory of Wealth in Retirement

David A. Love, Michael G. Palumbo, and Paul A. Smith, February 2008

The Rising Age at Retirement in Industrial Countries

Gary Burtless, February 2008

The Implications of Career Lengths for Social Security

Melissa M. Favreault and C. Eugene Steuerle, February 2008

Do Out-of-Pocket Health Care Costs Delay Retirement?

Richard W. Johnson, Rudolph G. Penner, and Desmond Toohey, February 2008

How the Income and Tax Treatment of Saving and Social Security Benefits May Affect Boomers' Retirement Incomes

Barbara A. Butrica, Karen E. Smith, and Eric J. Toder, February 2008

Saving and Wealth Accumulation in the PSID, 1984-2005

Barry P. Bosworth and Sarah Anders, February 2008

Older Women's Income and Wealth Packages in Cross-National Perspective

Timothy M. Smeeding, Janet C. Gornick, Eva Sierminska, and Maurice Leach, Feb. 2008

How Many Struggle to Get By in Retirement?

Barbara A. Butrica, Daniel Murphy, and Sheila R. Zedlewski, January 2008

The Impact of Late-Career Health and Employment Shocks on Social Security and Other Wealth

Richard W. Johnson, Gordon B.T. Mermin, and Dan Murphy, December 2007

All working papers are available on the Center for Retirement Research website

(http://www.bc.edu/crr) and can be requested bye-mail (crr@bc.edu) or phone (617-552-1762). 